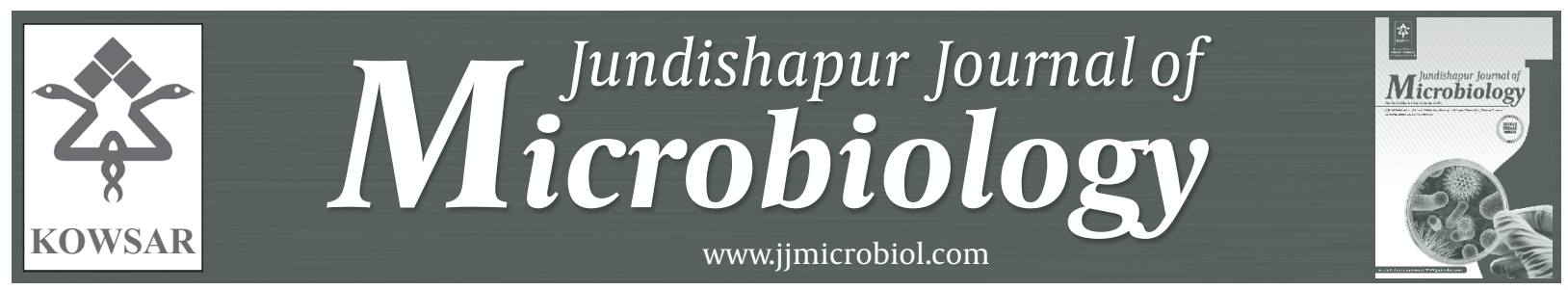

\title{
Mycoflora of Fungal Contamination in Wheat Storage (Silos) in Golestan Province, North of Iran
}

\author{
Hamidreza Joshaghani ${ }^{1}$, Mohadeseh Namjoo ${ }^{2}$, Masoumeh Rostami ${ }^{3}$, Faramarz Kohsar ${ }^{4}$, \\ Farhad Niknejad $^{2, *}$
}

${ }^{1}$ Golestan Research Center of Gastero Enterology and Hepatology, Golestan University of Medical Sciences. Gorgan, IR Iran

${ }^{2}$ Faculty of Paramedicine and Health, Golestan University of Medical Sciences, Gorgan, IR Iran

${ }^{3}$ Faculty of Medicine, Golestan University of Medical Sciences, Gorgan, IR Iran

${ }^{4}$ Faculty of Paramedicine and Health, Golestan University of Medical Sciences, Gorgan, IR Iran

*Corresponding author: Farhad Niknejad, 60 kola Roads- Falsafi Building, School of Paramedicine and Health, Golestan University of Medical Sciences, Gorgan, IR Iran. Tel: +98-1714436102-8, E-mail: fniknezhad@yahoo.com.

\begin{abstract}
A B S T R A C T
Background: Cereal products are susceptible to mould damage during pre- and post-harvesting stages of the production. The regional specificity of Golestan province in the northern region of of Iran, with its high temperature and high relative humidity, acts as a leading factor for the growth of aflatoxin-producing fungi. It is well known that contamination of starch-based ingredients with mycotoxigenic fungi is a risk factor among the consumers due to its aflatoxins.

Objectives: This survey was carried out to determine the extent of fungal contamination of wheat in three silos of Golestan province in Iran. Materials and Methods: 34 samples from three active silos were collected in order to clean the polyethylene bags. Wheat analyzed for fungal contamination and aflatoxins extracted by immunoaffinity column chromatography, and measured by HPLC method.

Results: The most common moulds isolated were Alternaria spp. 26.7\%, Aspergillus niger 21.4\%, Fusarium spp. 17.8\%, Aspergillus flavus 10.7\%, Cladosporium spp. 10.7\%, Penicillium spp. 8.9\%, and Rhizopus spp. 3.5\%. The screening of aflatoxin, B1, B2, G1 and G2 was carried out. 10(29.4\%) samples of wheat had traces of aflatoxin, but in a level lower than the standard levels [Institute of Standards and Industrial Research of Iran (ISIR\&lt; $15 \mathrm{ng} / \mathrm{g})]$.

Conclusions: Despite the lower detected aflatoxin levels (lower than the ISIR level), the fungal contamination rate could not be neglected. Since the isolated mycotoxigenic fungi such as Aspergillus spp. and Fusarium spp. are important in food industry, it would be possible that the increased retention time of samples might have raised the detected contamination rate.
\end{abstract}

Keywords: Wheat; Fungal Contamination; Aflatoxin

Copyright ( $\odot$ 2013, Ahvaz Jundishapur University of Medical Sciences; Published by Kowsar Corp.

Article type: Research Article; Received: 13 May 2012; Revised: 02 Jul 2012; Accepted:11 Jul 2012; Epub: 01 Jun 2013; Ppub: Jun 2013

Implication for health policy/practice/research/medical education:

The present study on wheat silo in Golestan province is the first survey of fungal contamination of cereal in Golestan Province and may be useful for further mycotoxin evaluation.

Please cite this paper as:

Joshaghani H, Namjoo M, Rostami M, Kohsar F, Niknejad F. Mycoflora of Fungal Contamination in Wheat Storage (Silos) in Golestan Province, North of Iran.Jundishapur J Microbiol. 2013;6(4):e6334. DOI:10.5812/jjm.6334.

Copyright @ 2013, Ahvaz Jundishapur University of Medical Sciences; Published by Kowsar Corp.

This is an Open Access article distributed under the terms of the Creative Commons Attribution License (http://creativecommons.org/licenses/by/3.0), which permits unrestricted use, distribution, and reproduction in any medium, provided the original work is properly cited. 


\section{Background}

Fungal contamination is one of the major causes of food spoilage. It not only brings about great economic losses, but also represents a high risk for human and animal health through the synthesis of mycotoxin (1-3). Mycotoxins are fungal secondary metabolites produced by some phytopathogenic spoilage fungi such as Aspergillus, Penicillium, Fusarium, and Alternaria species that are hazardous for consumers' health, and lead to economic losses of commercial value of food products (4). Toxicogenic Alternaria and Fusarium species are often classified as field fungi, while Aspergillus and Penicillium species are considered as storage fungi (5).

Mycotoxin production depends on various factors such as the presence of toxic fungi, chemical composition of the substrate, moisture, temperature, and time course of fungal growth (6). Cereal products are at risk to mould damage through pre- or post-harvesting stages of agriculture. Food products with high fungal contamination and higher humidity rates are susceptible to early spoilage if inappropriately stocked (7). Contamination of starch-based ingredients with mycotoxigenic fungi parallels the risk of mycotoxicosis among the consumers. Climate diversity of Golestan province, located in north of Iran, with its uniform high temperature and high relative humidity, may be a conducive factor for the growth of aflatoxin-producing fungi.

\section{Objectives}

Due to the importance of the contamination of starchbased ingredients with mycotoxigenic fungi and existence of any data on the natural occurrence of mycotoxigenic fungi and also the levels of wheat's aflatoxin in Golestan province, the present survey was conducted in order to determine the extent of fungal contamination of wheat in three silos of Golestan province in Iran.

\section{Materials and Methods}

\subsection{Sample Collection}

During 2008 and 2009, a total of 34 samples (500 g) of wheat from 3 active silos in Golestan province, North of Iran, including 14 reservoirs in Gorgan (Latitude36 ${ }^{\circ} 50^{\prime} \mathrm{N}$; Longitude: $54^{\circ} 44^{\prime} \mathrm{E}$ ), 11 reservoirs in Gonband (Latitude: $34^{\circ} 33^{\prime} \mathrm{N}$; Longitude: $\left.48^{\circ} 71^{\prime} \mathrm{S}\right), 17$ reservoirs in Galikesh (Latitude: $37^{\circ} 25^{\prime} \mathrm{N}$; Longitude: $55^{\circ} 48^{\prime} \mathrm{E}$ ) were collected in order to clean the polyethylene bags. Samples were submitted to the mycology laboratory at the University's mycology department, by the aim of assessing any possible fungal contaminations, aflatoxin determination, and fungal identification. The samples were stored at $4{ }^{\circ} \mathrm{C}$ until the beginning of laboratory analysis.

\subsection{Sample Preparation and Analysis}

Each sample (20 g) was surface disinfected for 2 minutes with $0.2 \%$ sodium hypochlorite solution and rinsed three times with sterile distilled water. From each sample, 40 grains were randomly selected and then put in Petri plates (90 mm diameter, 10 grains/dish) containing Sabouraud's dextrose agar (Merck, Darmstadt, Germany) with $5 \%$ chloramphenicol in duplicate. Petri plates were incubated at $25^{\circ} \mathrm{C}$ for 6 to 10 days. Each pure culture was characterized and identified based on their morphological and microscopic characteristics using the keys of Pitt and Hockings (2) and Raper and Fennel (8).

Aflatoxin concentrations were reported in $\mathrm{ng} / \mathrm{g}$ of wheat by immunoaffinity column chromatography method (Aflaclean, LCTech, Germany) and evaluated by HPLC system, consisting of a fluorescence detector (Knauer, Germany). Aflatoxins were separated on HPLC column with a mobile phase of water: methanol: acetonitrile (60:30:15, v/v/v), excitation and emission wavelengths of 365 and $440 \mathrm{~nm}$ respectively, flow rate of $1.2 \mathrm{ml} / \mathrm{min}$, and retention times of 25 minutes. The data were then analyzed using SPSS software (Version 15) and the Pvalue less than 0.05 was considered significant.

\section{Results}

\subsection{Fungal Isolation and Identification}

The most common moulds isolated were Alternaria spp. 26.7\%and A. niger $21.4 \%$ (Table 1). The screening of aflatoxin B1, aflatoxin B2, aflatoxin G1 and aflatoxin G2 was carefully performed. 10 (29.4\%) samples of wheat had traces of aflatoxin, but in a level lower than that of the Institute of Standards and Industrial Research of Iran (ISIR, $<15 \mathrm{ng} / \mathrm{g}$ ). No significant differences were observed between the contamination fungal isolates, and the aflatoxin in the grains $(\mathrm{P}>0.05)$.

Table1 . The Percentage of Wheat and Samples Containing Identified Fungal Genera

\begin{tabular}{ll}
\hline Fungal Isolates & No $^{\mathbf{a}}$.(\%) \\
\hline Alternaria spp. & $15(26.7)$ \\
\hline Aspergillus niger & $11(21.4)$ \\
\hline Fusarium spp. & $11(17.8)$ \\
\hline Aspergillus flavus & $6(10.7) \%$ \\
\hline Cladosporium spp. & $6(6)$ \\
\hline Penicillium spp. & $5(8.9)$ \\
\hline Rhizopus spp. & $2(3.5)$ \\
\hline Other & $3(0.3)$ \\
\hline
\end{tabular}

a wheat samples contamination 


\section{Discussion}

The purpose of the present study was to assess the fungal contamination of the selected wheat samples, and to subsequently determine the possible contaminations of these samples by aflatoxins. The contamination of wheat with microscopic filamentous fungi does not necessarily result in the presence of mycotoxins. The emergence of mycotoxins depends on several factors such as relative humidity, temperature, the properties of the substrate composition, and the degree of contamination (9). The optimal conditions for the growth and emergence of aflatoxins by fungi are different; and fungi optimally grow at about $30{ }^{\circ} \mathrm{C}$ and $0.95 \mathrm{aw}$, while mycotoxins' growth is optimal at about 25 to $30^{\circ} \mathrm{C}$ and 0.99 aw (10).

The fungal growth cannot only change the chemical and physical properties of the food products, but also the nutrient content of the grains. Beatriz Roigé in his research showed that Penicillium (42\%), Fusarium (27\%) and Alternaria (25\%) were the most frequently genera recovered from wheat (11). In the present study, members of the genus Alternaria spp. and A. niger were highly prevalent, while Fusarium spp. was the third more frequent fungus isolated from the wheat grains. High incidence rates of Alternaria spp. from different geographical areas of the Argentina have been observed in freshly harvested wheat, which is in close agreement with the findings of this research $(12,13)$.

The high frequency and abundance of Aspergillus spp. in the present study's findings could be due to failures in food production and conservation. Fusarium was isolated in 17.8 \% silage samples. Pelhate reported that Fusarium was present at harvesting as a result of field infection, and can no longer stay alive once the oxygen level reduces (14). Similar to the findings of our study, Abdel-Hafez et al. showed in their research that Alternaria spp. was the most prevalent fungi in harvested wheat and, sorghum dusts from Egypt and Aspergillus spp. ranked as the second place (15). Fusarium, Penicillium, Alternaria, Mucor and especially Aspergillus (belonging to section Flavi and Nigri) were the most important fungal species, and are commonly isolated from Algerian wheat species (16).

Aflatoxin B1 was detected in only 10 out of 34 wheat samples, and its abundance in only one sample was $6.91 \mathrm{ng} / \mathrm{g}$, which is more than the ISIR level $(<5 \mathrm{ng} / \mathrm{g})$. Although aflatoxigenic fungi were found at high levels in our study, total aflatoxins were found in levels lower than the ISIR level ( $<15 \mathrm{ng} / \mathrm{g}$ ). Therefore, it can be hypothesized that our strains were nontoxic or were not capable of producing aflatoxin up to dangerous levels of toxicity, and that toxin development needs a longer period of time.

Our results were consistent with the findings another research in Argentina that introduces most predominant fungal species of Alternaria and Fusarium as endogenous mycoflora (17); and another study, confirming that the most commonly isolated fungi from Algerian wheat are
Aspergillus spp., Fusarium spp., Penicillium spp., Alternaria spp. and Mucor spp. (16). A mycological survey on the stored wheat samples in Iran showed that 46 species belonging to 23 different genera fungi were isolated; and that Cladosporium spp. (57.1-89.2\%) and Alternaria spp. (82.4-100\%) species were the predominant fungal species as endogenous mycoflora (18).

According to our findings, A. niger with $21.4 \%$ ranked second in fungi isolated from wheat. This may be indicated that air fungal flora is variable in different areas. Although the number of analyzed samples was limited, our results revealed a relatively higher contamination of wheat grain. On the other hand, as a result of the continuous use of flour products in the diet, even a low level of contamination by aflatoxins may have adverse effects on human health. Moreover, it is feasible to decrease fungal contamination by sufficient education in the field of food industry, and favorable farm management.

Despite the fact that the total aflatoxin estimated in the samples was lower than the ISIR limits, the fungal contamination rate could not be neglected. Isolation of mycotoxigenic fungi such as Aspergillus spp. and Fusarium spp. Is of vital importance in the food industry. In the year of study due to shortage of wheat storage, the sources of sampling were not long-lasting, and, it is probable that the contamination would be raised with an increase in the retention time of samples.

\section{Acknowledgements}

The authors would like to thank the department of Research Affairs at Golestan University of Medical Sciences.

\section{Financial Disclosure}

The authors have no conflict of interests in relation to the material in the document.

\section{Funding/Support}

This work was fully sponsored by Deputy of Research, Golestan University of Medical Sciences, Gorgan, Iran.

\section{Authors' Contribution}

None declared.

\section{References}

1. MacDonald S, Prickett TJ, Wildey KB, Chan D. Survey of ochratoxin A and deoxynivalenol in stored grains from the 1999 harvest in the UK. Food Addit Contam. 2004;21(2):172-81.

2. Pitt JI, Hocking AD. Fungi and food spoilage. 1997.

3. Tutelyan VA. Deoxynivalenol in cereals in Russia. Toxicol Lett. 2004;153(1):173-9.

4. Moss MO. Recent studies of mycotoxins. Symp Ser Soc Appl Microbiol. 1998;27:62S-76S.

5. Logrieco A, Bottalico A, Moretti A, et al. Epidemiology of Toxigenic Fungi and their Associated Mycotoxins for Some Mediterranean Crops. EurJ Plant Pathol. 2003;109(7):645-667.

6. Placinta CM, D'Mello JPF, Macdonald AMC. A review of worldwide contamination of cereal grains and animal feed with Fusarium 
mycotoxins. Anim Feed SciTech. 1999;78(1-2):21-37.

7. Abdullah N, Nawawi A, Othman I. Survey of fungal counts and natural occurrence of aflatoxins in Malaysian starch-based foods. Mycopathologia.1998;143(1):53-8.

8. Raper KB, Fennell DI. The genus Aspergillus. 1965.

9. Gallo G, Lo Bianco M, Bognanni R, Saimbene G. Mycotoxins in durum wheat grain: hygienic-health quality of sicilian production. J Food Sci. 2008;73(4):T42-7.

10. Alam S, Shah HU, Magan N. Water availability affects extracellular hydrolytic enzyme production by Aspergillus flavus and Aspergillus parasiticus. World Mycotoxin J. 2009;2(3):313-322.

11. Roige MB, Aranguren SM, Riccio MB, Pereyra S, Soraci AL, Tapia MO. Mycobiota and mycotoxins in fermented feed, wheat grains and corn grains in Southeastern Buenos Aires Province, Argentina. Rev Iberoam Micol. 2009;26(4):233-7.

12. Broggi LE, Gonzalez HH, Resnik SL, Pacin A. Alternaria alternata prevalence in cereal grains and soybean seeds from Entre Rios, Argentina. Rev Iberoam Micol. 2007;24(1):47-51.

13. Medina A, Valle-Algarra FM, Mateo R, Gimeno-Adelantado JV, Mateo F, Jimenez M. Survey of the mycobiota of Spanish malting barley and evaluation of the mycotoxin producing potential of species of Alternaria, Aspergillus and Fusarium. Int J Food Microbiol. 2006;108(2):196-203.

14. Pelhate J. Maize silage: incidence of moulds during conservation. Folia Vet Lat. 1977;7(1):1-16.

15. Abdel-Hafez SI, Moubasher AH, Shoreit AA, Ismail MA. Fungal flora associated with combine harvester wheat and sorghum dusts from Egypt. J Basic Microbiol. 1990;30(7):467-79.

16. Riba A, Mokrane S, Mathieu F, Lebrihi A, Sabaou N. Mycoflora and ochratoxin A producing strains of Aspergillus in Algerian wheat. Int J Food Microbiol. 2008;122(1-2):85-92.

17. Gonzalez HH, Molto GA, Pacin A, Resnik SL, Zelaya MJ, Masana M, et al. Trichothecenes and mycoflora in wheat harvested in nine locations in Buenos Aires province, Argentina. Mycopathologia. 2008;165(2):105-14.

18. Kachuei Reza, Mohammad Hossein Yadegari, Sasan Rezaie, Abdolamir Allameh, Naser Safaie, Farideh Zaini, et al. Investigation of stored wheat mycoflora, reporting theFusarium cf.langsethiae in three provinces of Iran during 2007. Ann Microbiol. 2009;59(2):383-390. 